\title{
PROPAGANDAS \\ PUBLICITÁRIAS DE \\ CERVEJA E O PRIMADO \\ DO INTERDISCURSO: A \\ INTERDISCURSIVIDADE \\ COMO PILAR ENUNCIATIVO
}

\section{CAIO VINÍCIUS CATALANO \\ Doutorando em Letras pela Universidade Presbiteriana Mackenzie (UPM), São Paulo, SP, Brasil. E-mail: prof.catalano@hotmail.com}

\section{Resumo}

Todo texto é local de manifestação de discurso - um conjunto de conceitos imaginários concretizados pelo próprio emissor referentes aos interlocutores de uma situação enunciativa. Discurso é o suporte de materialização de ideologia. A relação polêmica entre discursos constitui a interdiscursividade, ou seja, a relação de discurso com discurso. O objetivo do presente artigo é a análise de três propagandas publicitárias, veiculadas em épocas diferentes (décadas de 1930,1970 e 2010) e tendo como tema central a venda de bebidas alcoólicas (cerveja), visando a identificar nesses textos alguns conceitos primordiais, formadores da ferramenta de análise denominada Análise do Discurso de linha francesa, como a noção de discurso e interdiscursividade, relacionando-os a outros conceitos advindos desses dois primeiros - sujeito enunciador, enunciatário, formação discursiva e cena enunciativa. Como suporte teórico, utilizaremos os postulados concebidos por teóricos consagrados, como Dominique Maingueneau. 


\section{Palavras-chave}

Análise do discurso. Textos publicitários. Interdiscursividade.

\section{INTRODUÇÃO}

O presente texto tem por objetivo a condução da análise de três propagandas publicitárias, que têm como mote a venda de bebida alcoólica, mais especificamente a venda de cerveja, visando a identificar nesses textos alguns conceitos primordiais, formadores da ferramenta de análise denominada Análise do Discurso de linha francesa $(\mathrm{AD})$, como a noção de discurso e interdiscursividade, relacionando-os a outros conceitos advindos desses dois primeiros - sujeito enunciador, enunciatário, formação discursiva, cena enunciativa etc. Utilizaremos, como suporte teórico para a referida análise, alguns postulados concebidos por teóricos consagrados e formadores dos estudos característicos da AD, como Dominique Maingueneau (2008; 2015). Faremos referência a algumas de suas obras mais importantes, utilizadas aqui como base bibliográfica, e que foram fundamentais para a execução deste exercício, como a obra Discurso e Análise do Discurso, publicada em 2015.

Para que possamos analisar um texto, seja ele publicitário ou não, segundo as premissas da $\mathrm{AD}$ de linha francesa, devemos, primeiramente, ter em mente que todo texto é, por excelência o local de manifestação do(s) discurso(s). Entendemos o conceito de discurso como a imagem que o emissor, tratado como enunciador ou sujeito-enunciador, faz de si e de seu receptor, concebido como enunciatário ou coenunciador (PÊCHEUX, 1969); ou seja, um conjunto de conceitos imaginários concretizados pelo próprio emissor referentes aos interlocutores de uma situação enunciativa. O discurso é concebido como o suporte de materialização da ideologia. Segundo Althusser (1983), a ideologia tem a função de ser uma representação, um simulacro entre a relação imaginária dos indivíduos e suas condições reais de existência. Possuindo uma materialidade, ou seja, uma existência material, é determinada a relação entre os Aparelhos Ideológicos dos Estados e a prática ideológica: "uma ideologia existe sempre em um aparelho e em sua prática ou práticas. Esta existência é material” (ALTHUSSER, 1983, p. 89). Representando relações reais de existência, as práticas materiais dos indivíduos são reflexos de suas ideologias.

Para dar continuidade ao exercício proposto, utilizaremos a concepção de Maingueneau (2015), conforme a tese do primado do interdiscurso, que aponta o discurso como um conjunto de regras definidoras da caracterização de uma 
determinada enunciação, regida por normas e apresentando um modo de análise como um "sistema no qual a definição da rede semântica que circunscreve a especificidade de um discurso coincide com a definição das relações desse discurso com seu Outro" (MAINGUENEAU, 2008, p. 40). Essa abordagem, proposta por ele, de conceber o termo discurso como um espaço interdiscursivo por excelência foi a utilizada para a análise do nosso corpus. O autor, seguindo as premissas postuladas por Pêcheux (1969) e Althusser (1983), considera o discurso uma realidade, ao mesmo tempo, inteiramente linguística e histórica.

Segundo essa concepção, o que determina o discurso é a sua enunciabilidade. Toda enunciação parte de um conjunto de regras definidoras de uma determinada formação discursiva; ou seja, está em conformidade com os preceitos e coerções que esta formação discursiva determina em detrimento das regras de constituição do discurso de seu "Outro". Enunciar é escolher determinada formação discursiva, adequar-se às suas condições de constituição e, por consequência, negar os traços semânticos que constituem, virtualmente ou concretamente, o "Outro" discursivo.

Retomando o conceito postulado por Maingueneau $(2008$; 2015) acerca do primado do interdiscurso, nos deparamos com a característica fundamental do discurso: esse fenômeno só é concebido com significância de sentido se relacionado ao universo interdiscursivo. Todo discurso, sendo atravessado pela interdiscursividade, advém de um interdiscurso (MAINGUENEAU, 2015).

Tomando como base as propagandas mencionadas como corpus para o exercício, verificamos que a relação entre os vários discursos que compõe cada enunciado é muito bem explicitada e passível de uma análise que caracterize e exemplifique o primado do interdiscurso. Identificaremos, primeiramente, esse fenômeno no texto abaixo retirado de uma propaganda da cerveja Malzebier (1925), conforme a figura abaixo:

Figura 1 - Malzbier

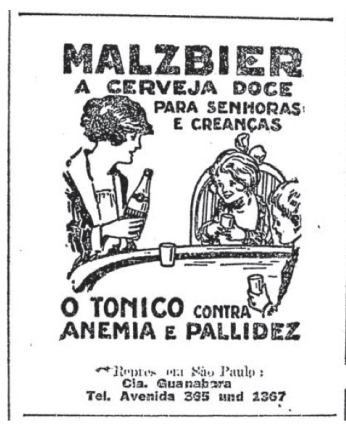

Fonte: Terra, 2014.

151 
Identificamos, primeiramente, que a propaganda pode gerar um certo estranhamento inicial por relacionar a bebida alcoólica à saúde ("tônico contra anemia e palidez") que, - atualmente, é vista como um produto que necessita de uma especial atenção com relação ao seu consumo, que deve ser moderado, conforme os conceitos médicos.

Há, no enunciado, uma relação harmônica entre o consumo da cerveja e o ambiente familiar, alegorizando o produto como um tônico fortificante, auxiliar na luta contra moléstias, como a anemia e a palidez. $\mathrm{O}$ estranhamento inicial é desmistificado se analisarmos o contexto histórico de produção da propaganda que, por ser da cerveja Malzbier, da cervejaria Brahma, veiculada na década de 1930, está em perfeita consonância com os preceitos e moralidades aceitos na sociedade brasileira na época; uma vez que ainda não haviam sido feitos estudos que comprovassem o efeito devastador da bebida alcoólica ou que remetesse seu consumo ao vício e caracterizada como uma droga lícita.

Não existe um esforço em renunciar uma possível problemática e consequente aproximação entre esses dois universos semânticos discursivos (bebidas alcoólicas e o vício), pois o discurso, como formador de ideologia, sugere que, na época, a saúde em contraste com o uso de drogas permitidas não era pungente no cenário nacional. $\mathrm{O}$ que prevalecia era um posicionamento, legitimado por especialistas da saúde, de que uma vivência saudável física era acarretada pelo uso de cerveja, visto com moderação, principalmente entre familiares, que pode ser verificado na primeira propaganda apresentada.

Conseguimos determinar dois campos discursivos muito bem definidos e que se complementam na busca da adesão discursiva do enunciatário. $\mathrm{O}$ enunciador, intentando a legitimação de seu discurso e a consequente sedução enunciativa, utiliza o campo discursivo da família atrelado ao campo da medicina, veiculando uma imagem robusta de equiparação ideológica entre dois conceitos chaves na compreensão do enunciado: a família e a saúde. A família, representada pela figura da mãe protetora e dos filhos, reunidos à mesa, é configurada no próprio bojo familiar, exemplificado com uma representação dócil e agradável, com largos sorrisos, aguardando o "néctar fortificante".

Essa aparente reunião festiva e saudável só é possível, segundo a ideologia apregoada no anúncio, se estiver vinculada à bebida alcoólica. É a própria cerveja que promove a união familiar, embasada pela saúde proporcionada 
pelo consumo. Esse discurso é ratificado no texto que se apresenta na figura, com vocábulos próprios da área médica (palidez e anemia). É forte a unificação entre esses dois campos discursivos, sendo a efetiva concretização ideológica de uma (família feliz) comprometida com a concretização discursiva de outro (família saudável).

Merece uma menção analítica o slogan do produto, que trata a cerveja como "doce". A expressão "cerveja doce", dentro do contexto discursivo a que se propõe o enunciado, serve como um amenizador, atenuando uma possível rejeição ao gosto amargo e forte, característico de grande parte das bebidas feitas de malte e cevada. O discurso remete a uma quebra ideológica, retirando a cerveja, em geral de uma esfera discursiva masculina, e a insere no contexto familiar relacionando a partir de seu sabor adocicado; a mãe zelosa e preocupada com o bem-estar de seus filhos e os próprios rebentos.

Essa simbiose discursiva, proveniente de uma formação ideológica engajada na conquista do enunciatário, é a representação clássica da interdiscursividade que perpassa toda e qualquer formação discursiva, conforme Maingueneau (2015). Assim, como a propaganda da cerveja Malzebier (1925), a Antarctica (1972) também busca a adesão de seu enunciatário, mas de forma diferente com relação à formação discursiva, conforme mostra a figura abaixo:

Figura 2 - Antarctica 1

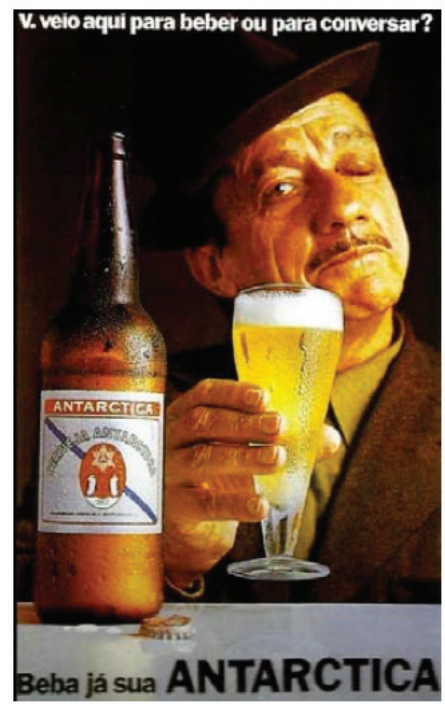

Fonte: Scholz, 2012. 
Como na primeira propaganda analisada, a publicidade da cerveja Antarctica também tem a preocupação em seduzir o enunciador, característica própria de qualquer discurso publicitário. No entanto, as duas propagandas apresentadas se diferem com relação ao foco enunciativo, que não se encontra mais no âmbito familiar. A publicidade da cerveja Antarctica se passa em um bar bastante característico da década de 1970, que pode ser percebido pelas representações visuais e verbais. Existe uma forte representação visual que compõe todo o cenário discursivo, tomando a cerveja da marca Antarctica como foco visual do anúncio. No caso da representação visual, o cantor, compositor e líder, na época, do grupo de samba paulistano, Demônios da Garoa, Adoniran Barbosa, é apresentado com uma sutil e convidativa piscadela, como um típico boêmio. O cantor segura, ao lado de uma garrafa de cerveja, o copo "suado", colocado em evidência no primeiro plano, na tentativa de despertar no enunciatário o desejo pelo produto.

A formação discursiva empregada nessa propaganda funciona como tentativa de impregnar ao produto da Antarctica um valor agradável, essencial e indubitável. Agradável, pois a cerveja representa o paladar refinado e satisfatório dos degustadores. Ela é tanto o refinamento degustativo quanto a saciedade líquida. Essencial, pois encontra-se no foco enunciativo da propaganda, em que todas as estratégias visuais e verbais gravitam em torno de sua figura. Indubitável, pois não há margem para dúvidas diante do posicionamento discursivo ratificado pelo enunciado assertivo "beba já sua Antarctica". Essa frase, utilizando um verbo no imperativo (beba) e um advérbio referente ao tempo imediato (já), coloca o enunciador em um posicionamento subalterno no jogo discursivo. Ele se vê na condição de acatar à ordem imposta pelo enunciador.

Os discursos aqui acionados são utilizados na busca da adesão do enunciatário. Uma estratégia enunciativa peculiar é verificada na pergunta situada na extremidade superior do anúncio: "veio aqui para beber ou para conversar?”. Essa pergunta enquadra-se na categoria de perguntas retóricas, já que não oferece subsídios semânticos e lexicais para uma escolha argumentativa. Esse fenômeno linguístico, por definição, não apresenta a obrigatoriedade de uma escolha como resposta ao questionamento. Muito pelo contrário: a própria formulação já desobriga esse raciocínio. Esse processo dispensa a participação do enunciatário, portanto o intelocutor não tem voz ativa na atividade discursiva. 
Como pudemos verificar por meio da análise do segundo anúncio, mais uma vez é exemplificado a prerrogativa e primazia do interdiscurso, que cataliza e possibilita inúmeros discursos circulantes no universo dos discursos, convergindo, num espaço discursivo específico, uma formação-composição característica (MAINGUENEAU, 2015).

Partiremos agora para a análise do último anúncio que compõe o corpus desse trabalho, que também será o foco final deste exercício. Demonstraremos que, assim como nos analisados anteriormente, este é um exímio representante da constante de interdiscursividade primeira, inerente a qualquer discurso. Segue abaixo e figura:

Figura 3 - Antarctica 2

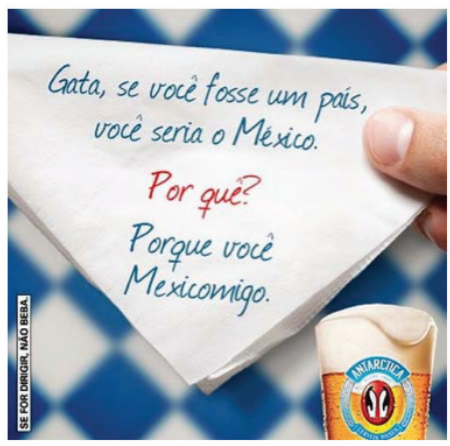

Fonte: Drconteudo, 2012.

O anúncio acima possui características próprias de enunciação, mas a sedução ideológica de seu interlocutor ainda é o ponto final de sua caminhada discursiva, assim como os outros dois anúncios analisados. Toda cenografia representada na publicidade remete a um ambiente característico de um bar. Porém, existem representações discursivas contrastantes com o bar anunciado anteriormente na Figura 2, delimitando um posicionamento ideológico diverso. Os apelos visuais apresentados são representativos de um boteco comum, como o guardanapo estampado no centro da figura, o posicionamento lateral inferior do copo de cerveja e o quadriculado característico da maioria dos pisos de botequins. Entretanto, ao analisar o texto grifado no centro do objeto de papel, é possível verificar um linguajar característico de uma classe social bem definida.

Tratando-se de um anúncio publicitário veiculado no ano de 2010, que busca atingir um público representativo dessa época, o sujeito enunciador, na 
condição de apregoador dos ideários veiculados em seu enunciado, utiliza um vocabulário que remete ao enunciatário mais jovem, que faz uso de expressões como "gata" para referir a futuras e pretendidas parceiras amorosas. Essa representatividade de um discurso "jovem" fica mais evidente quando analisamos todo o texto no centro do anúncio, em que há um jogo de palavras entre o verbo "mexer" - conjugado na terceira pessoa do presente do indicativo ("mexe") -, o vocábulo que designa o país da América do Norte ("México") e o pronome oblíquo tônico da primeira pessoa do singular ("comigo"). Esse tipo de artimanha enunciativa é característica de jogos amorosos utilizados pelo público juvenil e são expressivos dessa jovialidade descontraída.

Confirmamos que há uma clara preocupação na representação da cena discursiva, produzindo uma ambientação cenográfica que favoreça a aprovação desse interlocutor. Em contrapartida, não se verifica um discurso assumidamente comprometido com a venda e o consumo da bebida cerveja - representado, novamente, pela marca Antarctica. Todo enunciado visa o compromisso e a adesão ideológicos. Não negamos essa qualidade inerente da enunciação. O que determinamos para esse enunciado é o contraste que ele produz quando equiparado aos outros dois anúncios anteriores, que tinham posicionamentos discursivos muito bem definidos, quando pretendiam convencer o interlocutor consumidor a consumir o conteúdo veiculado no anúncio.

Diferentemente das estratégias utilizadas anteriormente nos dois primeiros anúncios analisados, a equiparação ideológica entre o discurso da saúde e o discurso da família e a utilização de enunciados assertivos e perguntas retóricas, o terceiro anúncio procura apenas representar um ambiente de descontração, alegria e jovialidade, não apregoando explicitamente nenhum posicionamento quanto à bebida alcoólica.

A relação entre um discurso relacionado ao bem-estar, à alegria, ao namoro e à paquera e um discurso voltado para o consumo do produto anunciado fica implícita, como para que se essa relação fosse concretizada, bastasse a veiculação da imagem da cerveja em um ambiente descontraído. Fica subentendido que toda a alegria e sentimento de paquera são permeados pelo consumo da cerveja, que aparece apenas no canto inferior direito, como um lembrete ao enunciatário da escolha discursiva que ele deve fazer. Toda a ideologia é apregoada de uma forma sutil, sem possíveis embates ideológicos. Assim, como uma situação de paquera e de consumo da cerveja, a busca da legitimação discursiva segue um percurso visual e verbal calmo, quase natural. 
Devemos levar em conta, contudo, um posicionamento arbitrário do enunciador quando faz referência a possíveis danos causados pelo consumo da bebida ligado ao ato de dirigir veículos automotores. Existe uma frase em tempo verbal de imperativo determinando a não ingestão do produto em caso de uso de tais veículos ("se for dirigir, não beba"). Mas mesmo tal posicionamento, que configura um discurso preocupado tanto com a saúde do interlocutor quanto com o cumprimento das leis que regem os anúncios publicitários, encontra-se em um canto à direita, quase que escondido, em letras menores e não destacadas, fora do eixo normal de leitura (vertical), revelando uma pouca preocupação na capitação de seu conteúdo por parte do consumidor. Essa estratégia enunciativa caracteriza também um posicionamento ideológico de época, exemplificando uma relação não tão saudável com bebidas alcoólicas, já tidas nesse contexto histórico, como drogas legalizadas, revela, portanto, um discurso contrário, doutrinador e repreensor.

Por fim, ressaltamos a referência ao primado do interdiscurso, que canoniza: toda enunciação que serve ao propósito do convencimento: todo discurso busca a adesão discursiva; toda ideologia se resguarda na sedução argumentativa e; todos esses fenômenos ganham corpo representativo tanto semântico, lexical quanto ideológico no interior de um interdiscurso. A interdiscursividade é a chave mestra que movimenta toda a relação discursiva/ideológica de qualquer manifestação enunciativa.

\section{Beer advertising and the interdiscursive primacy: the interdiscursivity as enunciative basis}

\section{Abstract}

Every text is a place for the expression of discourse - a set of imaginary concepts concretized by the transmitter referring to the interlocutors of an enunciative situation. Discourse is the support for the materialization of ideology. The polemical relation between discourses constitutes interdiscursivity, that is, the relation of discourse with discourse. The purpose of this article is to analyze three advertisements, published in different periods (1930s, 1970s, and 2010) and focused on the sale of alcoholic beverages (beer), aiming at identifying in these texts some primordial concepts, formators of the analysis tool called French Line Discourse Analysis, as the notion of discourse and interdiscursivity, relating them to other concepts derived from these two first ones - subject enuncia- 
tor, enunciate, discursive formation and enunciative scene. As a theoretical support, we will use the postulates conceived by established theorists, such as Dominique Maingueneau.

\section{Keywords}

Discourse analysis. Advertising texts. Interdiscourse.

\section{REFERÊNCIAS}

ALTHUSSER, L. Ideologia e aparelhos ideológicos de estado. Rio de Janeiro: Graal, 1983.

MAINGUENEAU, D. Discurso e análise do discurso. Trad. Sírio Possenti. São Paulo: Parábola, 2015.

MAINGUENEAU, D. Gênese dos Discursos. Trad. Sírio Possenti. São Paulo: Parábola, 2008.

DRCONTEUDO. Curadoria e Inspiração. Cervejas. Setembro de 2012. Disponível em: <http://drconteudo.com.br/2012/09/dr-conteudo-curadoria-e-inspiracao-cervejas/>. Acesso em: 24 jun. 2016.

PÊCHEUX, M. Analyse automatique du discourse. Paris: Dunod, 1969.

SCHOLZ, C. Vai beber ou conversar? Estadão, 2012. Disponível em: <http://www. estadao.com.br/blogs/reclames-do-estadao/vai-beber-ou-conversar/>. Acesso em: 24 jun. 2016.

TERRA. Nutrição. Cerveja já foi indicada para amamentar e trabalhar; entenda. 27 de junho de 2014. Disponível em: <http://saude.terra.com.br/nutricao/cerveja-ja-foi-indicada-para-amamentar-e-trabalharentenda,2f97c7b6e48d6410VgnVCM3000009 af154d0RCRD.html>. Acesso em: 24 jun. 2016. 